\title{
Bioaccessibility of Zinc from Yogurt and Determination of Total Concentration Using Slurry Sampling and Flame Atomic Absorption Spectrometry
}

\author{
Camila K. de Andrade, ${ }^{\oplus a}$ Jucimara K. de Andrade, ${ }^{b}$ Vanessa E. dos Anjos ${ }^{\circledR b}$ and \\ Sueli P. Quináia ${ }^{*, a}$
}

\author{
${ }^{a}$ Departamento de Química, Universidade Estadual do Centro-Oeste (UNICENTRO), \\ 85040-167 Guarapuava-PR, Brazil \\ ${ }^{b}$ Departamento de Química, Universidade Estadual de Ponta Grossa (UEPG), \\ 84030-900 Ponta Grossa-PR, Brazil
}

\begin{abstract}
The bioaccessibility of $\mathrm{Zn}$ during in vitro gastrointestinal digestion from yogurt was investigated. In addition, the methodologies of sample preparation (dry and wet digestion, and slurry sampling) for the determination of total concentration of $\mathrm{Zn}$ in yogurt by flame atomic absorption spectrometry were also compared in this work. In comparison with digestion procedures, the proposed slurry sampling is simple and less time-consuming procedure. The limit of quantification determined was $1.3 \mu \mathrm{g} \mathrm{g}^{-1}$. The concentrations of $\mathrm{Zn}$ in the Brazilian yogurt ranged from 3.40 to $5.62 \mu \mathrm{g} \mathrm{g} \mathrm{g}^{-1}$. The percentage of the bioaccessible fraction of $\mathrm{Zn}$ from the samples ranged from 10 to $26 \%$. This corresponds to an average daily intake of less than $2 \%$ of the metal for adults and children, suggesting that the Brazilian yogurt contributes with a low amount of $\mathrm{Zn}$ for the human diet.
\end{abstract}

Keywords: zinc, yogurt, slurry sampling, in vitro digestion, flame atomic absorption spectrometry

\section{Introduction}

Yogurt is a dairy product obtained from milk fermentation by lactic acid bacteria, usually Lactobacillus bulgaricus and Streptococcus thermophilus, which convert milk sugar (lactose) into lactic acid. ${ }^{1-3}$ It is a basic product that has been consumed worldwide, mainly by children and the elderly., 2,45 The popularity of yogurt, as part of the human diet, it has been increasing due to its beneficial effects and continuous modifications performed in the product for more nutritional effects and new flavors and consistencies. ${ }^{3,5}$ Moreover, this food has a similar composition as milk, with a high content of proteins and fats, vitamins, such as B2 and B12, and minerals ( $\mathrm{Ca}, \mathrm{Mg}, \mathrm{K}, \mathrm{Na}, \mathrm{Zn}, \mathrm{Fe}, \mathrm{Mn}$, and $\mathrm{Cu}$ ). ${ }^{2,6}$

Several elements are essential for living organisms due to its biological functions depending of concentration and chemical form. The lack or excess of these elements may be harmful to the human health.,4-7 For example, Zn acts in the structure and catalysis of metalloenzymes, besides being essential in the regulation of gene expression, stabilizing structures of DNA, RNA and ribosomes, besides other

*e-mail: spquinaia@gmail.com, spquinaia@unicentro.br important biological functions. ${ }^{89}$ The source of metals in yogurt can be natural, by environmental contamination, or through the manufacturing and packaging process.

Therefore, it is important to monitor the concentration of metallic species for food security and the quality of yogurt. Currently, these evaluations are based on the determination of the total concentration of elements in this food. Normally, the determinations of elements present in yogurt samples (complex matrix) have been carried out by sample preparation procedures combined with spectrometric analysis techniques, such as atomic absorption and emission. 2,6,7

Yogurt sample preparation is a critical step due to the complexity of the matrix (high content of organic compounds like proteins and fats), and the several stages with the possibility of loss of analytes, among others. Procedures as dry and wet digestions are used in the destruction of the organic matrix releasing the metals into the simplest solutions. ${ }^{10,11}$ However, it is known that some of these procedures, especially those that occur in open systems have disadvantages such as longer duration of sample preparation, use of large volumes of hazardous reagents, loss of analyte by volatilization or even contamination of the sample. ${ }^{12,13} \mathrm{In}$ 
order to reduce the handling and sample preparation time, slurry sampling is an alternative to the fast determination of different metals in food and environmental matrices. ${ }^{14,15}$ This method has advantages because it reduces the sample preparation time, enables the use of aqueous standards for calibration, and minimizes problems of contamination or loss of analyte..$^{12,14,16}$ Brandão et al. ${ }^{2}$ and Brandão et al. ${ }^{7}$ developed a methodology for the direct determination of $\mathrm{Zn}, \mathrm{Ca}$ and $\mathrm{Mg}$ in yogurt, using high resolution-continuum source flame atomic absorption spectrometry. The authors verified that slurries presented similar results as the traditional digestion method.

However, the determination of the total concentration of metallic ions in foods is not enough to evaluate the nutritional or toxic potential of the same. To obtain the real beneficial or malefic effects of these elements it is necessary to know their bioavailability (absorption) and the bioaccessibility (digestion). ${ }^{17,18}$ The bioavailability is the fraction of element that reaches the bloodstream from the gastrointestinal tract, that is, the fraction that is actually absorbed by the organism. ${ }^{18,19}$ Bioaccessibility refers to the release of the compounds from the food matrix into the gastric and intestinal juice in the gastrointestinal tract. ${ }^{17,20-23}$ The bioaccessibility of metals species depend on food matrix, metal characteristic, concentration and speciation of metals.

Nowadays, in vitro digestion simulation tests have been used in the determination of bioaccessibility. In vitro tests simulate what occurs in two distinct parts of the human digestive system: the stomach and the small intestine. With the use of artificial gastric and intestinal juices it is possible to imitate the human digestion process easily and with a low cost. ${ }^{23,24}$ Several studies ${ }^{24-27}$ reported in vitro bioaccessibility of nutrients (peptides, amino acids, proteins, etc.) from dairy products or yogurt. However, there is a lack of data regarding the release of minerals from yogurt and other dairy products in the simulated gastrointestinal environment.

In this sense, this work aims at the determination of total zinc contents in yogurt samples and the quantification of the bioaccessible fraction of this element by simulated in vitro digestion experiments. Flame atomic absorption spectrometry (FAAS) was used in the determination of zinc due to the low cost, quickness, and precise and accurate results. For the determination of the total zinc concentration in the samples, with other traditional methodologies for sample preparation (wet and dry-ashing digestion), the slurry sampling was compared. After comparison, the proposed methodology was optimized and validated. Moreover, it was possible to verify the bioaccessibility of $\mathrm{Zn}$ from Brazilian yogurt and to evaluate if the estimate of daily consumption of yogurt contributes to the nutritional intake of zinc.

\section{Experimental}

\section{Equipment, reagents and solutions}

Determinations of $\mathrm{Zn}$ were carried out by a Flame Atomic Absorption Spectrometer (Varian, SpectraA 220) equipped with multi-element hollow cathode lamp for $\mathrm{Zn}$, operating at $213.9 \mathrm{~nm}$ with a current of $5 \mathrm{~mA}$ and a slit width of $1 \mathrm{~nm}$. An air-acetylene flame, for the atomization of $\mathrm{Zn}$, was employed. The spectrometer operated under optimum conditions. The measurements of absorbance and background signals were carried out in triplicate. Other kinds of equipment were used in the preparation of samples, such as an ultrasonic bath of $40 \mathrm{kHz}$ (USC-2800 and USC-2800A, Unique), a heating plate (Fisatom and SPLabor), stove (Odontobras), muffle furnace (Quimis), shaker incubator (SP 222, SPLabor), pHmeter (Metrohm), and ultracentrifuge (Himac CR21GII, Hitachi).

In order to reduce or eliminate any source of sample contamination, procedures of cleaning techniques in this work were adopted..$^{15,28,29} \mathrm{All}$ reagents used were of analytical grade, with purity suitable for determination of trace metals. Solutions were prepared with high purity water (Thermo Scientific or Millipore). The working standard solutions of $\mathrm{Zn}$ were prepared by the dilution of $1000 \mathrm{mg} \mathrm{L}^{-1}$ stock standard solutions (Biotec, São Paulo, Brazil). For the sample preparation, nitric acid (Carlo Erba, Val de Reuil, France) and hydrochloric acid (Sigma-Aldrich, Saint Louis, USA) were used. Enzymes from Sigma-Aldrich Co. (Saint Louis, USA): pepsin from porcine gastric mucosa $\left(\geq 250\right.$ units $\left.\mathrm{mg}^{-1}\right)$, pancreatic from swine pancreas $(4 \times$ USP (United States Pharmacopeia) specifications) and bile salts were used in the bioaccessibility assays.

Throughout the study, solutions and samples were prepared in triplicate.

\section{Yogurt samples}

Yogurt samples were purchased from local supermarkets (Guarapuava and Ponta Grossa, Paraná, Brazil). Two types of yogurt (pasty and drinking yogurt) from distinct manufacturers (A, B, C) were used. All samples were stored at $4{ }^{\circ} \mathrm{C}$ until further processing. In Table 1 is presented the yogurt samples description.

Determination of total $\mathrm{Zn}$ concentration in yogurt by FAAS

Four procedures of yogurt sample preparation for 
Table 1. Information of the yogurt samples used in the quantification of $\mathrm{Zn}$ by FAAS

\begin{tabular}{lccc}
\hline Sample & Brand & Type $^{\mathrm{a}}$ & Description \\
\hline A1 & A & regular, pasty yogurt & whole \\
A2 & A & regular, pasty yogurt & semi-skimmed with flavor \\
A3 & A & regular, drinking yogurt & semi-skimmed with flavor \\
B1 & B & regular, pasty yogurt & skimmed \\
B2 & B & regular, pasty yogurt & skimmed with added honey \\
B3 & B & regular, pasty yogurt & whole with added fruit \\
C1 & C & regular, pasty yogurt & skimmed \\
C2 & C & regular, pasty yogurt & whole with added fruit \\
C3 & C & regular, pasty yogurt & whole with added fruit \\
C4 & C & regular, pasty yogurt & whole with added fruit \\
C5 & C & soy, drinking yogurt & soy yogurt with added fruit \\
\hline
\end{tabular}

'Regular: cow's yogurt.

total determination of $\mathrm{Zn}$ concentration by FAAS were tested. ${ }^{2,7,30}$ In these experiments, a sample of natural whole yogurt enriched with $50.0 \mathrm{\mu g} \mathrm{g}^{-1} \mathrm{Zn}$ was used. Dry-ashing digestion (DD) of yogurt sample was performed with drying of $1.0 \mathrm{~g}$ of sample for $3.5 \mathrm{~h}$ in the stove $\left(60{ }^{\circ} \mathrm{C}\right)$, followed by drying in water bath $\left(3.45 \mathrm{~h}, 95{ }^{\circ} \mathrm{C}\right)$ and drying on a heating plate $\left(2.5 \mathrm{~h}, 85^{\circ} \mathrm{C}\right)$. Finally, the sample was carbonized and, lastly, calcined in muffle $\left(3 \mathrm{~h}, 450{ }^{\circ} \mathrm{C}\right)$. Afterwards, the residues were solubilized in $3.0 \mathrm{~mL}$ of $\mathrm{HNO}_{3}\left(7 \mathrm{~mol} \mathrm{~L}^{-1}\right)$, being transferred to volumetric flask, added to $25 \mathrm{~mL}$ with ultrapure water. ${ }^{30}$ Wet digestion in beaker with reflux (WD-B) was tested with $1.0 \mathrm{~g}$ of the sample, $1.7 \mathrm{~mol} \mathrm{~L}^{-1} \mathrm{HNO}_{3}$ and $2.4 \%(\mathrm{v} / \mathrm{v})$ $\mathrm{H}_{2} \mathrm{O}_{2}$. The mixture was heated at $80{ }^{\circ} \mathrm{C}$ in sand bath for $2 \mathrm{~h}$. Subsequently, the solution was supplemented with ultrapure water to a final volume of $25 \mathrm{~mL} .^{2,7}$ Another method used was wet digestion with closed cryogenic tube (WD-CT). For this, $0.4 \mathrm{~g}$ of the sample with $1.7 \mathrm{~mol} \mathrm{~L}^{-1}$ $\mathrm{HNO}_{3}$ and $2.4 \%(\mathrm{v} / \mathrm{v}) \mathrm{H}_{2} \mathrm{O}_{2}$ were transferred to a cryogenic tube and heated $\left(85^{\circ} \mathrm{C}\right)$ in sand bath for $1 \mathrm{~h}$. Afterwards, the solution was transferred to the volumetric flask with a capacity of $10 \mathrm{~mL} \cdot{ }^{2,7} \mathrm{In}$ turn, slurry sampling (SS) was tested with $1.0 \mathrm{~g}$ of yogurt being diluted with $1.0 \mathrm{~mol} \mathrm{~L}^{-1}$ $\mathrm{HNO}_{3}$ or $\mathrm{HCl}$, in a volume of $25 \mathrm{~mL} .^{2}$ The slurries were placed in an ultrasonic bath for $20 \mathrm{~min}$ and afterwards, the slurries were analyzed directly by FAAS. For each procedure the analytical controls were evaluated, being used ultrapure water and reagents to prepare them.

The efficiency of the procedures was evaluated by recovery tests, for which the following equation was used: Recovery $(\%)=\left(\mathrm{C}_{\mathrm{F}}-\mathrm{C}_{\mathrm{I}}\right) \times 100 / \mathrm{C}_{\mathrm{A}}$, being $\mathrm{C}_{\mathrm{F}}=$ the concentration of fortified sample; $\mathrm{C}_{\mathrm{I}}=$ concentration of unfortified sample; and $\mathrm{C}_{\mathrm{A}}=$ concentration of analyte added to the sample. ${ }^{31}$
After choosing the most appropriate method (in this case SS) for sample preparation, a $2^{2}$ factorial design was performed in duplicate for each assay, with a central point in triplicate. The factors evaluated were the concentration of $\mathrm{HCl}\left(\mathrm{mol} \mathrm{L}^{-1}\right)(0.2(+1), 0(0)$ and $0.1(-1))$ and time (min) of ultrasonic agitation $(5(+1), 1(0)$ and $3(-1))$.

In-house validation study

After the optimization of the adequate method of sample preparation for the determination of total concentration of zinc by FAAS, a validation study was carried out using plain whole yogurt of the pasty type. This sample was chosen considering its complexity, and any interference could be an estimate for similar samples.

The calibration technique of the method was evaluated by the external standard method (ESM), aqueous solutions containing the metallic standard, and by the standard addition method (SAM), yogurt suspension containing the metallic standard. The linearity of curves was checked by applying a linear regression analysis with analysis of variance (ANOVA) and a lack-of-fit test at $95 \%$ confidence level. ${ }^{32}$ The statistical calculations were performed with the Action software. ${ }^{33}$

The limit of detection (LOD) and the limit of quantification (LOQ) were, respectively, calculated by 3 and 10 times the standard deviation of 10 measurements of the blank divided by the slope of the analytical curve. ${ }^{32}$

Repeatability tests were carried out with yogurt slurries prepared in triplicate and analyzed by FAAS on the same day. In intermediate precision tests, yogurt samples were prepared in the same way as the repeatability tests and analyzed by FAAS during five consecutive days. Relative standard deviations (RSD) and Horrat values 
were calculated as an estimate of the precision of the method. ${ }^{31}$

The accuracy of the method was evaluated using recovery tests with the yogurt sample at two levels of fortification for the element of interest. The sample was fortified with 12.5 and $25 \mu \mathrm{g} \mathrm{g}^{-1}$ of $\mathrm{Zn}$ and the determinations were performed before and after the enrichment. As in other tests, the choice of sample was based on complexity. Samples of natural and integral yogurt had sufficient complexity to estimate a possible interference, as in other samples. To check the statistical significance of recovery values, a $t$-test at $95 \%$ confidence level was applied, through the equation $t=($ recovery value -100$) \times(\mathrm{n}-1)^{1 / 2} / \mathrm{SD}(\mathrm{n}=$ number of measurements; $\mathrm{SD}=$ standard deviation of the replicates).

Determination and bioaccessibility of $\mathrm{Zn}$ from Brazilian yogurt

The total concentrations of $\mathrm{Zn}$ were quantified in the 11 yogurt samples from Brazil (Table 1). Significant differences were determined by ANOVA and Tukey tests (at $95 \%$ confidence level). All statistical analyses of the data were carried out with the Action software. ${ }^{33}$

Simulated in vitro digestion of yogurts (Table 1) was performed using a procedure adapted from the model developed by Stelmach et al. ${ }^{34}$ For gastric digestion, $2 \mathrm{~g}$ of yogurt (dissolved in $20 \mathrm{~mL}$ ultrapure water) with $2.5 \mathrm{~mL}$ simulated gastric juice $\left(0.2 \mathrm{~g} \mathrm{~L}^{-1}\right.$ pepsin in $0.1 \mathrm{~mol} \mathrm{~L}^{-1}$ $\mathrm{HCl}$ ) was incubated at $37{ }^{\circ} \mathrm{C}$ and $150 \mathrm{rpm}$ shaking for $2 \mathrm{~h}$. Subsequently, the sample was transferred to ice bath to stop the enzymatic digestion. The $\mathrm{pH}$ of mixture was corrected at 7.0 with $1.5 \mathrm{~mol} \mathrm{~L}{ }^{-1} \mathrm{NaHCO}_{3}$. Afterwards, it was added to the mixture $2.5 \mathrm{~mL}$ intestinal juice (0.15 $\mathrm{g} \mathrm{L}^{-1}$ pancreatin, $1.5 \mathrm{~g} \mathrm{~L}^{-1}$ bile salts in $0.1 \mathrm{~mol} \mathrm{~L}^{-1}$ $\mathrm{NaHCO}_{3}$ ). In this step, the sample was incubated at $37^{\circ} \mathrm{C}$ and $150 \mathrm{rpm}$ shaking for $2 \mathrm{~h}$. Digested samples were transferred to ice bath. The determination of $\mathrm{Zn}$ in the bioaccessible fraction by FAAS was performed after the centrifugation of the digested sample $\left(4^{\circ} \mathrm{C}, 10,000 \mathrm{rpm}\right.$, and $20 \mathrm{~min}$ ).

Considering the complexity of the enzymatic medium, the quantification of $\mathrm{Zn}$ in the bioaccessible fractions was performed after evaluation of some analytical characteristics. The linearity of the analytical curves was investigated in two different medium: curves with external standard (PE) and in enzymatic medium $\left(18.5 \mathrm{mg} \mathrm{L}^{-1}\right.$ of pepsin in gastric juice $+13.9 \mathrm{mg} \mathrm{L}^{-1}$ of pancreatin and $139 \mathrm{mg} \mathrm{L}^{-1}$ of bile salts in intestinal juice). The analytical curves were evaluated by linear regression with ANOVA and test of lack of fit in a level of $95 \%$ of confidence, using the statistical software Action. ${ }^{33}$
The LOD and LOQ were also calculated for the bioaccessibility procedure. The calculation was performed using the standard deviation of 10 measurements of analytical control, blank (procedure employing in the gastrointestinal study) multiplied by a factor of 3 or 10 times and divided by the slope of the analytical curve for $\mathrm{Zn}{ }^{32}$

The accuracy of the bioaccessibility procedure was evaluated by comparing $\mathrm{Zn}$ concentrations in the fractions obtained without and with treatment of the supernatant (chyme) resulting from the centrifugation of the yogurt sample digested by the enzymatic medium. For the digestion of chyme from yogurt samples (and analytical controls), the procedure described for wet digestion with closed cryogenic tube (WD-CT) was followed.

\section{Results and Discussion}

Determination of total $\mathrm{Zn}$ concentration in yogurt by FAAS

The determination of elements in yogurt requires a sample preparation prior to the FAAS analysis. In this study, it was evaluated the most frequently applied sample preparation procedures for food analysis. Techniques such as dry-ashing (DD), wet digestion with reflux in beaker (WD-B), wet digestion in cryogenic tube (WD-CT) and slurry preparation (SS) with assistance of ultrasound were compared (Table 2). In these experiments it was used a sample enriched with $50.0 \mu \mathrm{g} \mathrm{g}^{-1} \mathrm{Zn}^{2+}$. This was necessary due to the low content of $\mathrm{Zn}$ in the in nature sample, being that for all the evaluated procedures was performed the quantification in these non-enriched sample. $\mathrm{Zn}$, at the specified concentration, was added in the yogurt sample, and left overnight to increase the interaction of the metal with the matrix. In Table 2, the concentrations shown were subtracted from the analytical control (blank) and from the initial concentration of $\mathrm{Zn}$ in the sample. The initial concentration of $\mathrm{Zn}$ was determined in yogurt by FAAS and the values obtained were $5.7 \pm 0.1,6.6 \pm 0.2,6.6 \pm 0.1$, $5.1 \pm 0.1$ and $5.8 \pm 0.2 \mu \mathrm{g} \mathrm{g}^{-1}$ for DD, WD-B, WB-CT, SS with $\mathrm{HCl}$ and $\mathrm{SS}$ with $\mathrm{HNO}_{3}$, respectively. In this case, it was possible to observe that $\mathrm{Zn}$ concentration in yogurt was close in the different methods of sample prepare. The recovery value was obtained in relation to the added content and the results were evaluated by the Tukey's test.

In Table 2, it can be observed that concentrations of Zn determined in the samples using different preparations were close to the expected concentration $\left(50.0 \mu \mathrm{g} \mathrm{g}^{-1}\right)$. Therefore, recovery values ranged from 91 to $103 \%$, which is within the acceptable range (80-110\%) considering the studied concentration. ${ }^{31}$ Recovery values for $\mathrm{Zn}$ in yogurt 
Table 2. Comparison among different techniques of sample preparation and determination of $\mathrm{Zn}$ in yogurt by FAAS. Data of determined concentrations, recoveries and statistical analysis are shown

\begin{tabular}{lcclc}
\hline $\begin{array}{l}\text { Sample } \\
\text { preparation }\end{array}$ & $\mathrm{Zn}^{\mathrm{a}} /\left(\mu \mathrm{g} \mathrm{g}^{-1}\right)$ & Recovery /\% & Tukey's test $^{\mathrm{b}}$ \\
\hline WD-B & $48.3 \pm 0.1$ & 97 & $\mathrm{~B}$ & \\
WD-CT & $46.7 \pm 0.6$ & 93 & $\mathrm{~B}$ & $\mathrm{C}$ \\
DD & $45.6 \pm 0.8$ & 91 & $\mathrm{C}$ & \\
SS with $\mathrm{HCl}$ & $51.4 \pm 0.2$ & 103 & $\mathrm{~A}$ & \\
SS with $\mathrm{HNO}_{3}$ & $50.8 \pm 0.5$ & 102 & A & \\
\hline
\end{tabular}

a Concentrations determined were reported as mean \pm standard deviation of triplicate; ${ }^{b}$ means that do not share a letter are significantly different at $95 \%$ confidence level. WD-B: wet digestion in beaker with reflux; WD-CT: wet digestion with closed cryogenic tube; DD: dry-ashing digestion; SS: slurry sampling.

were adequate $(100 \pm 10 \%)$ in all procedures of the sample preparation. Comparing the slurry sampling (procedure proposed in this work), with procedures routinely used in the laboratory to determine metals in foods such as yogurt (wet and dry-ashing digestion, for example), it is possible to verify that the ratio between the determined concentrations in each procedure is close to 1 . This indicates that SS presents efficiency in the determination of $\mathrm{Zn}$ by FAAS. The statistical analysis (Tukey's test) showed that the results obtained with the wet digestion (WD-B and WD-CT) were similar. The results obtained with WD-CT were similar to the dry-ashing (DD). And the slurry sampling with $\mathrm{HCl}$ and $\mathrm{HNO}_{3}$ also had similar results. Even though it was observed that the $\mathrm{Zn}$ recoveries through the slurry sampling were larger (closer to $100 \%$ ), the difference between this faster method and the sample treatment methods happened mainly due to the possible loss of $\mathrm{Zn}$ during steps of preparation of the samples, for the traditional methods. Even so, in all cases, the recovery of the metal was within the expected. Thus, slurry preparation with assistance of ultrasound was chosen due to the reduction of acid consumption and sample preparation time (20 $\mathrm{min}$ ), besides presenting adequate and comparable recovery results, in relation to the reference procedures.

The type of acid used in the slurry preparation can have consequences in the measurements by atomic spectrometry. In this sense, we tested the use of $\mathrm{HNO}_{3}$ and $\mathrm{HCl}$ (possible formation of volatile and difficult-to-dissociate analyte chlorides causing interferences). No analytical problem was determined, and $\mathrm{HCl}$ was the chosen acid to dilute yogurt samples in the slurry sampling. Similar results are found in studies ${ }^{2,7}$ of slurry sampling of yogurt, which demonstrated the efficiency of the direct method in the quantification of metals such as $\mathrm{Zn}, \mathrm{Mg}$ and $\mathrm{Ca}$ in this matrix type using $\mathrm{HCl}$ as diluent.
These previous studies have demonstrated that the slurry sampling for preparation of the yogurt sample, under conditions described in the literature, provides adequate results when compared with traditional sample preparation procedures. However, optimizing a method or a process corresponds to improving the performance of the system as much as possible, and thus obtaining the greatest possible benefit from it. ${ }^{35}$ This may be related to the shorter sample preparation time or lower reagent consumption, for example.

Thus, after the choice of slurry sampling (SS), an optimization of the sample preparation conditions was performed. This study was conducted by $2^{2}$ factorial design with a central point to verify the possibility of further reducing the use of $\mathrm{HCl}$ and the time of ultrasonic agitation. Experiments were performed in duplicate, with exception of the central point (triplicate), and yogurt samples fortified with $25.0 \mu \mathrm{g} \mathrm{g}^{-1}$ of $\mathrm{Zn}$. The matrix of $2^{2}$ factorial design for SS and determined concentrations of $\mathrm{Zn}$ were showed in Table 3.

Table 3. Results obtained for $\mathrm{Zn}$ in the $2^{2}$ factorial design performed for optimization of the slurry sampling

\begin{tabular}{lccc}
\hline Assay & $\mathrm{HCl} /\left(\mathrm{mol} \mathrm{L}^{-1}\right)$ & $\mathrm{t} / \mathrm{min}$ & Results: $\mathrm{Zn}^{\mathrm{a}} /\left(\mu \mathrm{g} \mathrm{g}^{-1}\right)$ \\
\hline 1 & absence $(-1)$ & $1(-1)$ & $26.9 \pm 0.3(\mathrm{n}=2)$ \\
2 & absence $(-1)$ & $5(+1)$ & $26.5 \pm 0.7(\mathrm{n}=2)$ \\
3 & $0.2(+1)$ & $1(-1)$ & $26.4 \pm 0.3(\mathrm{n}=2)$ \\
4 & $0.2(+1)$ & $5(+1)$ & $26.2 \pm 0.1(\mathrm{n}=2)$ \\
Central point & $0.1(0)$ & $3(0)$ & $25.9 \pm 0.1(\mathrm{n}=3)$ \\
\hline
\end{tabular}

${ }^{\mathrm{a}}$ Concentrations determined were reported as mean \pm standard deviation and they were subtracted from the analytical control (blank) and from the initial concentration of $\mathrm{Zn}$ in the samples.

In Table 3, it was observed that the concentrations of $\mathrm{Zn}$ determined in the factorial design experiments ranged from $25.9 \pm 0.1$ to $26.9 \pm 0.3 \mu \mathrm{g} \mathrm{g}^{-1}$ (close to the concentration of $\mathrm{Zn}$ added in the samples, $\left.25.0 \mu \mathrm{g} \mathrm{g}^{-1}\right)$. Thus, recovery values were adequate (80-110\%) ranging from 104 (central point) to $108 \%$ (assay 1). Therefore, the reduction of acid and time of ultrasonic agitation can be performed without compromising the results for slurry sampling.

A statistical analysis of the factorial design was performed, and the principal and interactions effects were calculated. Effect values were presented in relation to the $t$-test at $95 \%$ confidence level. Effects for $\mathrm{HCl}$ and time of ultrasonic agitation were -1.66 and -1.24 , respectively. The interaction effect value between the factors was 0.41 . Considering freedom degree for factorial design, the standard error to the effects was $t_{\text {critical }}=2.45$, which is higher than the values obtained for the factors or their 
interaction. This showed that none of the evaluated factors influenced the determination of $\mathrm{Zn}$ in yogurt using SS, probably because the experimental conditions were in an optimal range.

Studies reported in literature ${ }^{2}$ using $2.0 \mathrm{~mol} \mathrm{~L}^{-1} \mathrm{HCl}$ in the yogurt slurry preparation also obtained adequate recovery for $\mathrm{Zn}$. Therefore, in this work it was possible to reduce the amount of reagents in the slurry preparation. The optimized condition was yogurt slurry (40.0 $\left.\mathrm{g} \mathrm{L}^{-1}\right)$ with $0.2 \mathrm{~mol} \mathrm{~L}^{-1} \mathrm{HCl}$ and $1 \mathrm{~min}$ of ultrasonic agitation. A lower level of one factor (acid concentration) was not chosen because this situation could lead to some kind of problem for the FAAS, such as the clogging of the capillary injection, or even a building up of residue on the atomizer equipment. Adding $\mathrm{HCl}$, even in low concentrations, can help to destroy the organic matrix of the yogurt, and thus, facilitate the determination of $\mathrm{Zn}$ by FAAS.

\section{In-house validation study}

The instrumental calibration of the developed method for the determination of $\mathrm{Zn}$ by slurry sampling and FAAS was evaluated by comparison of the external standardization and standard addition. This was done in order to check the sensitivity and matrix interference. Analytical curves for $\mathrm{Zn}$ were obtained in an aqueous solution (ESM) and standard addition curves were obtained with a yogurt matrix (SAM). Concentrations of $\mathrm{Zn}$ ranged from 0.1 to $1.6 \mathrm{mg} \mathrm{L}^{-1}$ for 7 points used in this study. Absorbance data were used to calculate a linear regression and coefficient of determination $\left(\mathrm{R}^{2}\right)$. The results obtained for ESM and SAM, and the tests of linearity of curves are shown in Table 4.

As it can be observed in Table 4, the curves showed similarities and good values for coefficient of determination $\left(\mathrm{R}^{2}>0.99\right)$. The slopes of the external standard and standard addition curves showed no statistical differences and the ratio between both slopes was close to 1 , indicating that the curves showed the same sensitivity. This suggests that there is no effect of the yogurt matrix in the determination of $\mathrm{Zn}$ by slurry sampling and FAAS. Thus, these results also indicated that the analytical curve in an aqueous solution could be used for the quantification of $\mathrm{Zn}$ in yogurt slurry by FAAS. This presents a great advantage to the method, because it increases the analytical frequency and reduces the costs of analyses (e.g., lower consumption of reagents and gas carrier).

Linear regression models were studied using $F$-test at 95\% confidence level for both calibrations type (Table 4 ). $F_{\text {regression }}$ values were higher than $F_{\text {critical }}$ values, indicating that the linear regression is significant for ESM and SAM. The linearity of curves can be confirmed by lack-of-fit tests $\left(F_{\text {lof }}\right)$ at a confidence level of $95 \%$ (Table 4$) . F_{\text {lof }}$ values (5.57 for ESM and 2.66 for SAM, respectively) were lower than the $F_{\text {critical }}$ values (6.94), indicating that $F_{\text {lof }}$ values were not significant in the confidence level adopted $(p>0.05)$ for both curves. Thus, there was no lack-of-fit of the constructed linear models, showing that the linearity of the curves for $\mathrm{Zn}$ is acceptable. Therefore, the external standard can be used in the quantification of $\mathrm{Zn}$ in yogurt with a linear range between LOD and $1.6 \mathrm{mg} \mathrm{L}^{-1}$ of $\mathrm{Zn}$.

The LOD and LOQ for the method were evaluated. The limits were low, with values of 0.4 and $1.3 \mu \mathrm{g} \mathrm{g}^{-1}$ for LOD and LOQ, respectively.

With regard to precision, results were expressed in terms of RSD and Horrat value. RSD values were 1.06 and $3.34 \%$ for repeatability tests (same day) and intermediate precision (five consecutive days), respectively. These values were adequate, being lower than $10 \% .{ }^{31}$

The results for intermediate precision can also be estimated in terms of Horrat value, whose proposed acceptable value is lower than $1.3 .{ }^{36}$ The result obtained for Horrat was 0.43 , being, thus, appropriate. Therefore, the method can be considered precise, with low variability of the results between measurements made on the same day or on different days.

Accuracy of the developed method was evaluated by recovery tests. Certified reference material (CRM) of yogurt is not marketed. The most similar certified reference material is milk. However, the consistency and viscosity of milk is very different from the yogurt. As the proposed method involves the slurry sampling of yogurt, the CRM of milk was not used, and the accuracy of the method

Table 4. Calibration parameters and linearity data for determination of $\mathrm{Zn}$ in yogurt

\begin{tabular}{|c|c|c|c|c|c|c|}
\hline & \multicolumn{2}{|l|}{ Regression parameter } & \multicolumn{4}{|c|}{ Validation of linearity } \\
\hline & \multirow{2}{*}{ Equation } & \multirow{2}{*}{$\mathrm{R}^{2}$} & \multicolumn{2}{|c|}{ Regression } & \multicolumn{2}{|c|}{ Lack-of-fit } \\
\hline & & & $F_{\text {obs }}{ }^{\mathrm{a}}$ & $p$-Value & $F_{\text {lof }}^{b}$ & $p$-Value \\
\hline ESM & $\mathrm{A}=(0.001 \pm 0.001)+(0.088 \pm 0.001) \times \mathrm{C}_{\mathrm{Zn}}$ & 100.0 & $14,520.79$ & 0.000 & 5.57 & 0.070 \\
\hline SAM & $\mathrm{A}=(0.007 \pm 0.002)+(0.086 \pm 0.002) \times \mathrm{C}_{\mathrm{Zn}}$ & 99.9 & $5,158.43$ & 0.000 & 2.66 & 0.184 \\
\hline
\end{tabular}

${ }^{\mathrm{a}} F_{\text {critical }}(1,6,0.05)$ for linear regression $=5.99 ;{ }^{\mathrm{b}} F_{\text {critical }}(2,4,0.05)$ for lack-of-fit $=6.94 . \mathrm{R}^{2}$ : coefficient of determination; ESM: external standard method; SAM: standard addition method; A: absorbance; $\mathrm{C}_{\mathrm{Zn}}$ : $\mathrm{Zn}$ concentration. 
was determined by recovery tests, which is considered adequate by the AOAC. ${ }^{31}$ Recovery for $\mathrm{Zn}$ in yogurt was $106 \pm 1 \%(\mathrm{n}=3)$ (for the highest concentration added), and $103 \pm 1 \%(\mathrm{n}=3)$ (for the lowest concentration added). The recovery was adequate considering an acceptable range of $80-110 \% .^{31} \mathrm{~A} t$-test was performed to verify the significance between the observed and desired values for recovery of the metal in yogurt. The $t_{\text {calculated }}$ values $(4.67$ for both concentrations) were lower than the $t_{\text {critical }}$ (12.706) at $95 \%$ confidence level. This result indicates that there is no significant difference between the recovery values for $\mathrm{Zn}$ in yogurt, compared to the desired value for recovery (100\%). Comparing the results for concentrations of $\mathrm{Zn}$ obtained by slurry sampling in relation to the dry-ashing procedure (used as reference), it was possible to observe ratios close to 1. This also demonstrates that the method of direct analysis of $\mathrm{Zn}$ in yogurt by FAAS presents adequate accuracy.

The application of the slurry sampling for total quantification of $\mathrm{Zn}$ in Brazilian yogurt and the determination of bioaccessible fraction of $\mathrm{Zn}$

The bioaccessibility procedure employed was adapted from the literature, ${ }^{34}$ and after in-house validation, it has been used in the research group in similar studies. The $\mathrm{Zn}$ quantification using curves with external standard (aqueous solution) can be performed. This was possible because differences in the slope of the curve with external standard in relation to the analytical curve constructed in enzymatic medium (in the presence of gastric and intestinal juices) were not observed in linearity tests (Table 5). Furthermore, a lack of adjustment of the proposed linear model was not observed. Thus, in the total quantification of $\mathrm{Zn}$ and determination of the bioaccessible fractions of the metal from the yogurt, it was possible to use analytical curve with external standard. Data related to the linearity of the analytical curves were presented in Table 5.

The LOD and LOQ values obtained for bioaccessibility procedure of $\mathrm{Zn}$ from yogurt were 0.04 and $0.12 \mu \mathrm{g} \mathrm{g}^{-1}$. Precision tests also indicated the suitability of the method (with values less than 10\%) for determinations of bioaccessible fractions of $\mathrm{Zn}$ from yogurt. In the evaluation of accuracy, the chyme from yogurt samples (and blanks) was digested using the procedure described for WD-CT. In this study, the bioaccessible fractions (in percentage) of $\mathrm{Zn}$ in yogurt were $36 \pm 6$ (chyme digested by WD-CT) and $28 \pm 2$ (chyme only centrifuged). The achievement of adequate results for these parameters demonstrated the applicability of the proposed procedure for the bioaccessibility of $\mathrm{Zn}$ from yogurt.

The total concentration of $\mathrm{Zn}$ and its bioaccessibility were determined in the 11 commercial samples of Brazilian yogurt (three plain yogurts, seven flavored yogurts or with added fruit and one soy yogurt) of 3 different brands, according to Table 1. The results can be observed in Figure 1.

As it can be observed in Figure 1a, the plain yogurt samples (A1, B1 and C1) had $\mathrm{Zn}$ concentrations that ranged from $5.5 \pm 0.1$ to $6.2 \pm 0.4 \mu \mathrm{g} \mathrm{g}^{-1}$. A1 sample is whole and $\mathrm{B} 1$ and $\mathrm{C} 1$ are skimmed yogurts, however, the concentrations were similar (A1 with B1 and A1 with $\mathrm{C} 1$ ). Samples of flavored yogurt or with added fruit presented $\mathrm{Zn}$ concentrations of $3.40 \pm 0.02 \mu \mathrm{g} \mathrm{g}^{-1}$ (A3) to $6.2 \pm 0.1 \mu \mathrm{g} \mathrm{g}^{-1}$ (B2), and soy yogurt (C5) presented a $\mathrm{Zn}$ concentration of $3.7 \pm 0.2 \mu \mathrm{g} \mathrm{g}^{-1}$. A significant difference between $\mathrm{Zn}$ concentrations was observed by performing the Tukey's test at $95 \%$ confidence, which demonstrates the variability of the content of this micronutrient in the matrix of interest. For the same brand, differences were observed among samples. For brands A and B, the corresponding samples were placed in different groups, showing the variability between them. For brand $\mathrm{C}$, with exception of $\mathrm{C} 1$ (plain yogurt), all samples presented similar concentration of $\mathrm{Zn}$. In this work, the total concentrations of $\mathrm{Zn}$ in yogurt ranged from 3.40 (A3) to $6.2 \mu \mathrm{g} \mathrm{g}^{-1}$ (B3, C1), and a mean of $4.6 \pm 1.1 \mu \mathrm{g} \mathrm{g}^{-1}$. These concentrations are in agreement with those found in other studies of quantification of metals in yogurt. Brandão et al. ${ }^{2}$ found $\mathrm{Zn}$ concentrations in Brazilian yogurt that ranged from 2.12 to $4.82 \mu \mathrm{g} \mathrm{g}^{-1}$. Llorent-Martínez et al. ${ }^{6}$ evaluated yogurt samples from Spain and found concentrations for $\mathrm{Zn}$ in the range from 1.5 to $4.5 \mu \mathrm{g} \mathrm{g}^{-1}$.

Table 5. Calibration parameters and linearity data for determination of $\mathrm{Zn}$ in the bioaccessible fractions from yogurt

\begin{tabular}{|c|c|c|c|c|c|c|}
\hline & \multicolumn{2}{|l|}{ Regression parameter } & \multicolumn{4}{|c|}{ Validation of linearity } \\
\hline & \multirow{2}{*}{ Equation } & \multirow{2}{*}{$\mathrm{R}^{2}$} & \multicolumn{2}{|c|}{ Regression } & \multicolumn{2}{|c|}{ Lack-of-fit } \\
\hline & & & $F_{\mathrm{obs}}{ }^{\mathrm{a}}$ & $p$-Value & $F_{\text {lof }} \mathrm{b}^{\mathrm{b}}$ & $p$-Value \\
\hline ESM & $\mathrm{A}=(0.008 \pm 0.001)+(0.015 \pm 0.003) \times \mathrm{C}_{\mathrm{Zn}}$ & 99.9 & 12896.94 & 0.000 & 5.21 & 0.077 \\
\hline SAM & $\mathrm{A}=(0.007 \pm 0.002)+(0.016 \pm 0.005) \times \mathrm{C}_{\mathrm{Zn}}$ & 99.9 & 5240.96 & 0.000 & 6.22 & 0.059 \\
\hline
\end{tabular}

${ }^{\mathrm{a}} F_{\text {critical }}(1,6,0.05)$ for linear regression $=5.99 ;{ }^{\mathrm{b}} F_{\text {critical }}(2,4,0.05)$ for lack-of-fit $=6.94 . \mathrm{R}^{2}$ : coefficient of determination; ESM: external standard method; SAM: standard addition method; $\mathrm{A}$ : absorbance; $\mathrm{C}_{\mathrm{Zn}}$ : $\mathrm{Zn}$ concentration. 

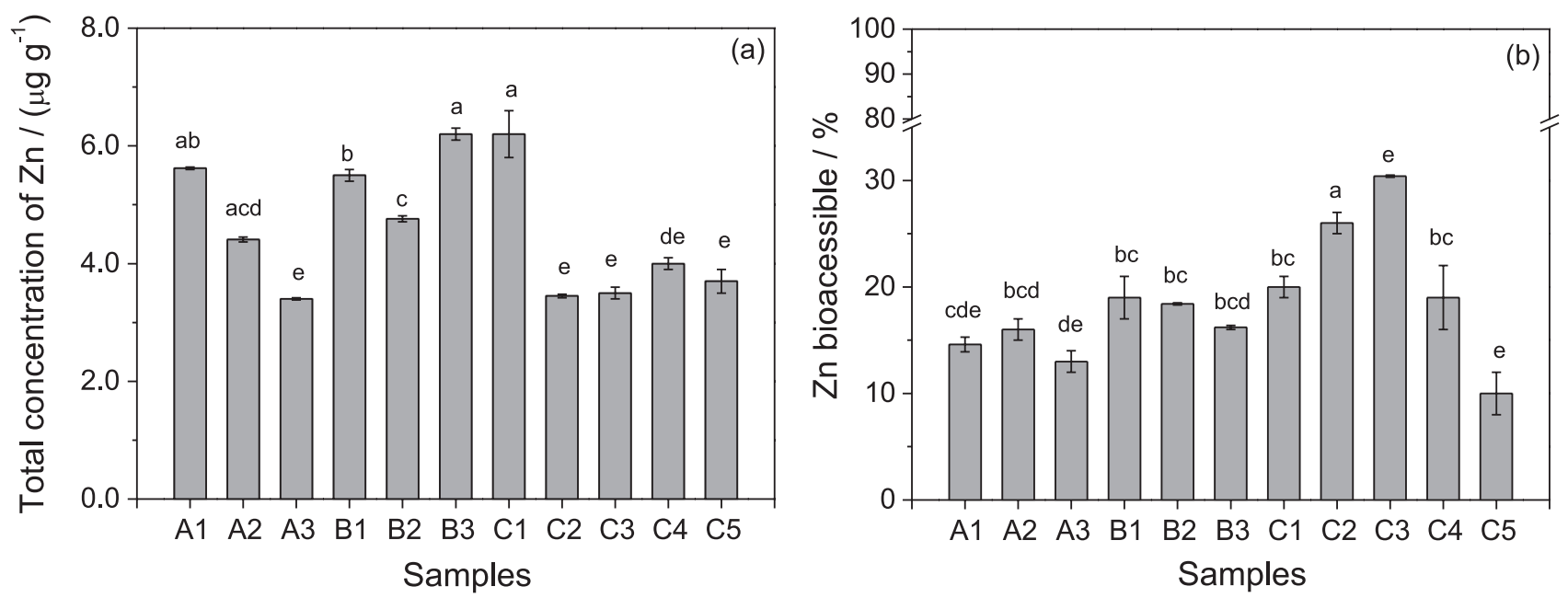

Figure 1. (a) Total concentration and (b) bioaccessible fractions of $\mathrm{Zn}$ in yogurts. Values were reported as mean \pm standard deviation ( $\mathrm{n}=3$ ) and they were subtracted from the analytical control (blank). Small letter above the data represent the application of the Tukey's test at 95\% confidence level. Similar letters mean similar data.

The sample type for yogurt is very wide, due to the large amount of products available, with pasty and liquid (ready to drink) options; natural products and others with essences and additions of fruit, honey and cereals; whole, semi-skimmed and skimmed products; products derived from cow milk (regular) and soy. In this study, a wide variety of products was evaluated, and it was verified similarities and differences among samples. For example, the $\mathrm{Zn}$ concentrations were different between pasty yogurt (A2) and drinking yogurt (A3). The levels of $\mathrm{Zn}$ were also similar between regular yogurt (A3) and soy yogurt (C5). The addition of fruit and flavor influenced the total concentrations of $\mathrm{Zn}$ in the samples. The concentration for whole yogurt (A1) was $5.62 \pm 0.02 \mu \mathrm{g} \mathrm{g}^{-1}$ and for whole yogurt with addition of fruit (B3, C2, C3 and C4) the mean values were $4 \pm 1 \mu \mathrm{g} \mathrm{g}^{-1}$. The whole samples with higher fat content presented similar contents of total zinc as semi-skimmed and skimmed products. For whole yogurt (B3 and C2), semi-skimmed (A2) and skimmed (B2), the mean values were $4 \pm 1,4.41 \pm 0.04$ and $4.76 \pm 0.05 \mu \mathrm{g} \mathrm{g}^{-1}$, respectively.

As $\mathrm{Zn}$ can present benefits or damages for health of living beings depending on the concentration ingested, it is necessary to assess if this product is suitable for human consumption making a calculation of estimation of the daily intake.

Considering a frequent consumption of this food (160 g per day), the values intake of $\mathrm{Zn}$ through the consumption of $160 \mathrm{~g}$ of yogurt per day ranged from 0.54 to $0.99 \mathrm{mg} \mathrm{day}^{-1}$, and a mean value of $0.74 \pm 0.18 \mathrm{mg} \mathrm{day}^{-1}$.

The values of recommended dietary allowance (RDA) of $\mathrm{Zn}$ intake for children range from 3 to $8 \mathrm{mg}$ per day, ${ }^{37-39}$ and for adults the value could be from 7 to $11 \mathrm{mg}$ of
Zn per day. ${ }^{37-39}$ Considering the maximum value of RDA for children and adults, the consumption of Brazilian yogurt represents the average intake of $9 \pm 2 \%$ of $\mathrm{Zn}$ in relation to the recommended for children and $6.7 \pm 1.6 \%$ of $\mathrm{Zn}$ in relation to the recommended for adults. These results can indicate that the Brazilian yogurt effectively contributes to the intake of zinc. However, this estimate does not represent the amount of $\mathrm{Zn}$ that can actually be absorbed by the human body with the consumption of yogurt. As it is known, the conditions of consumption, composition and interactions of the food with the gastrointestinal system can significantly influence the bioaccessibility of metals such as $\mathrm{Zn}$ in the human organism.

Thus, in Figure $1 \mathrm{~b}$ it can also be observed the bioaccessible fraction of $\mathrm{Zn}$ for the studied samples. It can be verified that the bioaccessibility of $\mathrm{Zn}$ was lower than $30 \%$ of the total concentration for all the samples. In general, considering that $\mathrm{Zn}$ has important biological functions for living beings, acting, for example, as a co-factor of enzyme, the bioaccessibility of $\mathrm{Zn}$ was expected to be significant. Nevertheless, due to interaction of metal with the enzymes during gastrointestinal simulation (as observed in complementary studies) and the yogurt composition itself, it can be observed that $\mathrm{Zn}$ absorption through yogurt consumption is low. In addition, the presence of proteins such as casein (in greater quantity), fats and other metals such as iron and calcium in this type of food, can act as inhibitors of $\mathrm{Zn}$ absorption, significantly reducing the bioavailability of this metal to the organism. ${ }^{40}$

Among the brands evaluated, brand A presented the lowest average for bioaccessibility of $\mathrm{Zn}$ in yogurt (14.5\%). As for brand C, it presented the highest average for bioaccessibility of $\mathrm{Zn}(21 \%)$ except for C5, 
which presented a lower bioaccessible fraction of $\mathrm{Zn}$ in yogurt (10\%). A Tukey's test (Figure 1b) showed that most of the samples were arranged in similar groups, that is, the bioaccessible fractions of $\mathrm{Zn}$ were very similar. Only sample C2 remained in a single group, since it had the highest bioaccessible fraction of $\mathrm{Zn}(26 \%)$ when compared to the other samples.

With respect to the smallest bioaccessible fraction of $\mathrm{Zn}$ presented by sample $\mathrm{C} 5$, the fact that this yogurt is produced with soybean can have contributed for this result. Diets based on plant products generally contain inhibitors of mineral absorption, such as phytic acid or phytate, polyphenols, oxalate and fiber. ${ }^{41}$ In this case, phytates are known to be the major inhibitors of $\mathrm{Zn}$ uptake in plants base. As well as peanut, rice, corn and other cereals, soybean also presented significant phytate content. Therefore, the lowest bioaccessible fraction of $\mathrm{Zn}$ presented by soy yogurt can be related with the presence of inhibitors as phytates, which, through the binding with zinc in an insoluble complex in the gastrointestinal tract, reduces the amount of zinc available for absorption.

From the bioaccessibility data it was possible to estimate the absorption of zinc through the consumption of yogurt in a way which is closer to the real one rather than estimate by the total concentration. It is noticed that the content to be absorbed is lower than $30 \%$ of the total content (bioaccessible fraction). With the consumption of $160 \mathrm{~g}$ of yogurt per day, the values of $\mathrm{Zn}$ intake (based on the bioaccessible fraction) ranged from 0.059 to $0.198 \mathrm{mg} \mathrm{Zn} \mathrm{day}^{-1}$, and a mean value of $0.13 \pm 0.04 \mathrm{mg} \mathrm{Zn} \mathrm{day}{ }^{-1}$. Considering the maximum value of RDA for children and adults as 8 and $11 \mathrm{mg} \mathrm{day}^{-1}$, respectively, ${ }^{37-39}$ calculations were performed. The consumption of Brazilian yogurt represents the average intake of $1.6 \pm 0.5 \%$ of $\mathrm{Zn}$ in relation to the recommended for children and $1.2 \pm 0.4 \%$ of $\mathrm{Zn}$ in relation to the recommended for adults. These values were well below the levels estimated by the total content ( 9 and $6 \%$ of $\mathrm{Zn} \mathrm{day}^{-1}$ for children and adults, respectively). These results indicated that the Brazilian yogurt contributes with small values to the intake of $\mathrm{Zn}$ in relation to the RDA. Therefore, bioaccessibility studies are essential in the nutritional assessment of a given food.

\section{Conclusions}

This study showed that slurry sampling with assistance of ultrasound was adequate for the direct determination of Zn by FAAS without prior digestion. A factorial design also demonstrated the robustness and, consequently, the precision of the method. Determinations of the total concentration of $\mathrm{Zn}$ can be performed by external standard analytical curves, which aid to increase the analytical frequency and decrease the costs of analysis. Validation tests demonstrated that the developed method is sensitive, presenting low values of LOD and LOQ, accuracy and precision. Thus, it shows that slurry sampling can be applied in the direct determination of total $\mathrm{Zn}$ in commercial yogurt samples. Zn concentration obtained in yogurt samples from Brazil are in agreement with those found in yogurts from other countries. Furthermore, in vitro tests showed that the bioaccessibility of $\mathrm{Zn}$ in yogurt is low, which may be related to the presence of absorption inhibitors of the metal in the yogurt composition. In relation to RDA of $\mathrm{Zn}$ for adults and children, this value is lower than $2 \%$, which demonstrates that yogurt does not appear to be a good source of this metal for the human diet. In this sense, bioaccessibility studies contribute to assessing whether foods can be nutritional or toxic sources of elements for living beings.

\section{Acknowledgments}

The authors would like to thank Conselho Nacional de Desenvolvimento Científico e Tecnológico (CNPq), Fundação Araucária, Financiadora de Estudos e Projetos (Finep), and Coordenação de Aperfeiçoamento de Pessoal de Nível Superior (CAPES). They also thank Complexo de Laboratórios Multiusuários (C-LabMu) of the Universidade Estadual de Ponta Grossa (UEPG) for the infrastruture offered. C. K. A. and J. K. A. thank CAPES for PhD scholarship.

\section{References}

1. Vedamuthu, E. R. In Manufacturing Yogurt and Fermented Milks; Vedamuthu, E. R.; Chandan, R. C.; White, C. H.; Kilara, A.; Hui, Y. H., eds.; Blackwell Publishing Professional: Iowa, USA, 2006, ch. 6.

2. Brandão, G. C.; Jesus, R. M.; Silva, E. G. P.; Ferreira, S. L. C.; Talanta 2010, 81, 1357.

3. Luis, G.; Rubio, C.; Revert, C.; Espinosa, A.; González-Weller, D.; Gutiérrez, A. J.; Hardisson, A.; J. Food Compos. Anal. 2015 , $39,48$.

4. Wang, H.; Livingston, K. A.; Fox, C. S.; Meigs, J. B.; Jacques, P. F.; Nutr. Res. 2013, 33, 18.

5. Hekmat, S.; McMahon, D. J.; J. Dairy Sci. 1997, 80, 3114.

6. Llorent-Martínez, E. J.; de Córdova, M. L. F.; Ruiz-Medina, A.; Ortega-Barrales, P.; Microchem. J. 2012, 102, 23.

7. Brandão, G. C.; Matos, G. D.; Ferreira, S. L. C.; Microchem. J. 2011, 98, 231.

8. Scherz, H.; Kirchhoff, E.; J. Food Compos. Anal. 2006, 19, 420.

9. Gharibzahedi, S. M. T.; Jafari, S. M.; Trends Food Sci. Technol. 2017, 62, 119.

10. Mendes, T. M. F. F.; Baccan, S. N.; Cadore, S.; J. Braz. Chem. 
Soc. 2006, 17, 168.

11. Korn, M. G. A.; da Boa Morte, E. S.; dos Santos, D. C. M. B.; Castro, J. T.; Barbosa, J. T. P.; Teixeira, A. P.; Fernandes, A. P.; Welz, B.; dos Santos, W. P. C.; dos Santos, E. B. G. N.; Korn, M.; Appl. Spectrosc. Rev. 2008, 43, 67.

12. Magalhães, C. E. C.; Arruda, M. A. Z.; Quim. Nova 1998, 21, 459.

13. Sardans, J.; Montes, F.; Peñuelas, J.; Spectrochim. Acta, Part B 2010, 65, 97.

14. Dobrowolski, R.; Pawlowska-Kapusta, I.; Dobrzynska, J.; Food Chem. 2012, 132, 597.

15. de Andrade, C. K.; de Brito, P. M. K.; dos Anjos, V. E.; Quináia, S. P.; Food Chem. 2018, 240, 268.

16. Krawczyk, M.; J. Pharm. Biomed. Anal. 2014, 88, 377.

17. Intawongse, M.; Dean, J. R.; TrAC, Trends Anal. Chem. 2006, $25,876$.

18. Bosso, S. T.; Enzweiler, J.; Quim. Nova 2008, 31, 394.

19. Carbonell-Capella, J. M.; Buniowska, M.; Barba, F. J.; Esteve, M. J.; Frígola, A.; Compr. Rev. Food Sci. Food Saf. 2014, 13, 155 .

20. Oomen, A. G.; Hack, A.; Minekus, M.; Zeijdner, E.; Cornelis, C.; Schoeters, G.; Verstraete, W.; Wiele, T. V.; Wragg, J.; Rompelberg, C. J. M.; Sips, A. J. A. M.; Wijnen, J. H. V.; Environ. Sci. Technol. 2002, 36, 3326.

21. Hu, J.; Wu, F.; Wu, S.; Cao, Z.; Lin, X.; Wong, M. H.; Chemosphere 2013, 91, 455.

22. Henderson, R. G.; Verougstraete, V.; Anderson, K.; Arbildua, J. J.; Brock, T. O.; Brouwers, T.; Cappellini, D.; Delbeke, K.; Herting, G.; Hixon, G.; Wallinder, I. O.; Rodriguez, P. H.; Assche, F. V.; Wilrich, P.; Oller, A. R.; Regul. Toxicol. Pharmacol. 2014, 70, 170.

23. Machado, I.; Cesio, M. V.; Pistón, M.; Microchem. J. 2017, 133, 663.

24. Turgeon, S. L.; Rioux, L.; Food Hydrocolloids 2011, 25, 1915.

25. Rinaldi, L.; Gauthier, S. F.; Britten, M.; Turgeon, S. L.; LWT-Food Sci. Technol. 2014, 57, 99.

26. Rinaldi, L.; Rioux, L.; Britten, M.; Turgeon, S. L.; Int. Dairy J. 2015, 46, 39.

27. Lamothe, S.; Rémillard, N.; Tremblay, J.; Britten, M.; Food Res. Int. 2017, 92, 138.

28. Campos, M. L. A. M.; Bendo, A.; Viel, F. C.; Quim. Nova 2002,
25,808 .

29. dos Anjos, V. E.; Abate, G.; Grassi, M. T.; Quim. Nova 2010, $33,1307$.

30. Zenebon, O.; Pascuet, N. S.; Tiglea, P. In Métodos FísicoQuímicos para Análise de Alimentos; Zenebon, O.; Pascuet, N. S.; Tiglea, P., eds.; Instituto Adolfo Lutz: São Paulo, Brasil, 2008, ch. 23.

31. Association of Official Analytical Chemists (AOAC); Official Methods of Analysis of AOAC International, Appendix F Guidelines for Standard Method Performance Requirements; AOAC: Gaithersburg, 2012.

32. Araújo, P.; J. Chromatogr. B 2009, 277, 2224.

33. Action, version 2.7; Estatcamp, Brazil, 2014. Available at http:// www.portalaction.com.br, accessed in August 2019.

34. Stelmach, E.; Pohl, P.; Szymczycha-Madeja, A.; J. Braz. Chem. Soc. 2014, 25, 1993.

35. Bezerra, M. A.; Santelli, R. E.; Oliveira, E. P.; Villar, L. S.; Escaleira, L. A.; Talanta 2008, 76, 965.

36. González, A. G.; Herradora, M.Á.; Asuero, A. G.; Talanta 2010, $82,1995$.

37. Institute of Medicine (IOM); Dietary Reference Intakes for Vitamin A, Vitamin K, Arsenic, Boron, Chromium, Copper, Iodine, Iron, Manganese, Molybdenum, Nickel, Silicon, Vanadium, and Zinc; National Academic Press: Washington DC, USA, 2001.

38. Food and Agriculture Organization/World Health Organization (FAO/WHO); Vitamin and Mineral Requirements in Human Nutrition; Joint FAO/WHO Expert Consultation: Bangkok, Thailand, 1998.

39. Agência Nacional de Vigilância Sanitária (ANVISA); Resolução RDC No. 269; Regulamento Técnico Sobre a Ingestão Diária Recomendada (IDR) de Proteína, Vitaminas e Minerais; ANVISA: Brasília, 2005.

40. Lönnerdal, B.; J. Nutr. 2000, 130, 1378S.

41. Lazarte, C. E.; Carlsson, N.; Almgren, A.; Sandberg, A.; Granfeldt, Y.; J. Food Compos. Anal. 2015, 39, 111.

Submitted: July 22, 2019

Published online: September 3, 2019 